Çukurova Üniversitesi Mühendislik Mimarlık Fakültesi Dergisi, 33(4), ss. 155-164, Aralık 2018

Çukurova University Journal of the Faculty of Engineering and Architecture, 33(4), pp. 155-164, December 2018

\title{
Seralarda Latent Isının Isı Gereksinim Katsayısına Etkisinin Belirlenmesi
}

\author{
A. Nafi BAYTORUN ${ }^{* 1}$, Zeynep ZAİMOĞLU ${ }^{2}$, Özkan GÜĞERCİN ${ }^{1}$ \\ ${ }^{1}$ Çukurova Üniversitesi, Ziraat Fakültesi Tarımsal Yapılar ve Sulama Bölümü, Adana \\ ${ }^{2}$ Çukurova Üniversitesi, Mühendislik Fakültesi Çevre Mühendisliği Bölümü, Adana
}

Geliş tarihi: $12.02 .2018 \quad$ Kabul tarihi: 25.12 .2018

$\ddot{\mathbf{O} z}$

Seralarda 1sı kayıpları örtü malzemesinin özelliğine bağlı transmisyon ve istenmeyen açıklılardan infiltrasyon ile meydana gelen 1sı kayıplarından oluşmaktadır. Seralarda kullanılan örtü malzemelerinin 1S1 gereksinim katsayıları örtü iç yüzeyindeki konveksiyon ve radyasyon 1sı iletim dirençleri dikkate alınarak belirlenmektedir. Oya bitkisel üretimin yapıldığı seralarda örtü iç yüzeyinde ortaya çıkan yoğunlaşma önemli miktarda latent ısının dış ortama taşınmasına neden olur.

Yapılan bu çalışmada bitkisel üretimin yapıldığı seralarda örtü iç yüzeyinde ortaya çıkan yoğunlaşma dikkate alınarak farklı örtü ve sera donanımlarında ortaya çıkan dirençler dikkate alınarak basit bir yöntemle 1S1 gereksinim katsayısının hesaplanması amaçlamışırı.

Yapılan çalışmada direnç modeliyle hesaplanan 1sı geçirgenlik katsayıları uygulamada yapılan ölçümlerle elde edilen sonuçlarla uyum göstermiştir. Türkiye'deki tüm plastik seralarda kullanılan katkılı PE plastik sera için uygulamadaki ölçümlerle $4.08 \mathrm{~W} \cdot \mathrm{m}^{-2} \mathrm{~K}^{-1}$ belirlenmiş olan transmisyon 1 sı iletim katsayısı, direnç metoduyla örtü iç yüzey ısı iletim katsayısının $h_{i}=15 \mathrm{~W} \cdot \mathrm{m}^{-2} \mathrm{~K}^{-1}$ olduğu koşullarda $4.23 \mathrm{~W} \cdot \mathrm{m}^{-2} \mathrm{~K}^{-1}$ olarak belirlenmiştir. Elde edilen sonuçlar direnç modelinin, yalıtımı iyi seralarda infiltrasyon isı kayıplarının çok küçük olması nedeniyle 1Sı gereksinim katsayısının hesaplanmasında kolaylıkla kullanılabileceğini göstermektedir.

Anahtar kelime: Isı tüketim katsayıs1, Isı iletim katsayısı, Latent 1s1, Is1 perdesi

\section{Determination of the Effect of Latent Heat on the Heat Requirement Coefficient in Greenhouses}

\begin{abstract}
The heat losses in greenhouses due to the characteristics of the cover material consist of transmission and cause of infiltration from undesired openings. Heat requirement coefficients of the covering materials that it is used in greenhouses are determined by indicating the convection and radiation heat conduction resistances on the inner surface of the covering. However, condensation on the inner surface of the cover in greenhouses where vegetative production is carried out causes a significant amount of latent heat to be transported to the external environment.
\end{abstract}

\footnotetext{
*Sorumlu yazar (Corresponding author): A. Nafi BAYTORUN, baytorun@cu.edu.tr
} 
In this study, it is aimed to examine the heat requirement coefficient in a basic way by taking into consideration the resistances occurring in different covering and greenhouse equipment by taking into account the concentration occurring in the inner surface of the cover in the greenhouses where vegetative production is made.

According to the study, the heat permeability coefficients calculated by the resistance model were in the same direction with the results obtained in the application. All additives used in plastic greenhouse PE with practical measurements for plastic greenhouses $4.08 \mathrm{~W} \cdot \mathrm{m}^{-2} \mathrm{~K}^{-1}$ of the determined transmission heat transfer coefficient in Turkey resistance method with the shroud inner surface heat transfer coefficient $h_{i}=15$ W.m ${ }^{-}$ ${ }^{2} \mathrm{~K}^{-1}$ with the condition that $4.23 \mathrm{~W} \cdot \mathrm{m}^{-2} \mathrm{~K}^{-1}$ has been determined. According to the results, the resistance model can be used easily in the calculation of the heat requirement coefficient due to the fact that the infiltration heat losses are very small in the insulating greenhouses.

Keywords: Heat consumption coefficient, Heat conductivity coefficient, Latent heat, Energie screen

\section{GíRiș}

Seralar bitkiler için gerekli olan büyüme etmenlerini (sıcaklık, nem, 1şık, $\mathrm{CO}_{2}$ ) optimum düzeyde tutabildiklerinden açık alanda yapılan üretime göre oldukça yüksek verim sağlayan teknik donanıma sahip yapılardır. Buna ek olarak uygun yetiştirme koşullarının sağlanması nedeniyle üretim periyodunun uzaması verimi artırıcı etki yaratmaktadır. Ancak modern seracılığa yapılan yatırım yüksek kapital gerektirmektedir. Özellikle seranın kurulduğu yerdeki iklim koşullarına bağlı olarak ortaya çıkan 1sıtma giderleri, üretimin sürdürülebilirliğini zorlamaktadır. Sürekli artan enerji fiyatları 1sıtmanın üretim giderleri içindeki payını yükseltmektedir. Akdeniz iklim koşullarında ssitma giderleri üretim giderlerinin \%20-25'ini kapsamaktadır [1]. Günümüzde yapılan üretimin ekonomikliğini sorgulamak için düşük enerji gereksinimi gösteren üretim programlarına veya üretim yöntemlerine ihtiyaç duyulmaktadır.

Seralarda enerji gereksinimini hesaplayan yeterli sayıda model bulunmaktadır. Kullanılan model ne kadar fazla parametre gerektiriyorsa o derece karmaşıktır. Modellerde kullanılan parametreler kabaca tahmin ediliyor veya varsayllyorsa, elde edilen sonuçlardan yüksek güvenirlik beklenemez. Belirtilen nedenle kullanılacak modeller mümkün olduğunca az parametre gerektirmeli ve uygulamadaki sonuçlarla uyuşmalıdır. Almanya'daki seralar için oluşturulmuş HORTEX ve Türkiye'deki farklı iklim bölgeleri için ısıtma sistemi parametrelerini ve 1s1 gereksinimini hesaplayan ISIGER-SERA bu modellere örnek verilebilir $[2,3]$.

Seralarda 1sı gereksinimi Eşitlik 1 temel ilişkisi ile belirlenmektedir $[2,4,5]$.

$\Phi=\sum_{\mathrm{n}=1}^{8760} \mathrm{U}_{\mathrm{cs}} * \mathrm{~A}_{\mathrm{c}} *\left(\theta_{\mathrm{i}}-\theta_{\mathrm{e}}\right)-\mathrm{q}_{\mathrm{s}} * \mathrm{~A}_{\mathrm{G}} * \tau * \eta$

Eşitlikte;

$\Phi$ : Is1 gereksinimi (W)

$U_{c s}$ : Isı gereksinim katsayısı $/ \mathrm{W} / \mathrm{m}^{2} \mathrm{~K}$ )

$A_{c}$ : Sera örtü yüzey alanı $\left(\mathrm{m}^{2}\right)$

$\theta_{i}-\theta_{e}$ : İç ve dış ortam sıcaklık farkı (K)

$q_{s}$ : Güneş 1şınımı $\left(\mathrm{W} / \mathrm{m}^{2}\right)$

$A_{G}$ : Sera taban alanı $\left(\mathrm{m}^{2}\right)$

$\tau$ : Örtü malzemesinin geçirgenliği (-)

$\eta$ : Işınımın duyulur ısıya dönüşüm faktörü (-)

Eşitlik 1'in birinci bölümü seradan meydana gelen 1S1 kayıplarını tanımlamaktadır. Eşitliğin bu bölümündeki ısı gereksinim katsayısı $\left(U_{c s}\right)$ farklı etmenler tarafından etkilenmektedir. Bunlar sırasıyla örtü malzemesinin özelliği, sera donanımı, rüzgar hızı, gökyüzü koşulları (bulut, gökyüzü Sıcaklığı) 1sıtma sistemi ve evapotranspirasyondur. Eşitlik 1 'in ikinci bölümü güneşten kazanılan enerjiyi tanımlamaktadır. $\eta$ üretimin yapılmadı $\breve{~} 1$ boş sera için 1.0 olarak kabul edilirken, yaprak/alan 
indeksi (LAI) yüksek olan domates veya hıyar gibi bitkilerin yetiştirildiği sera için koşullara bağlı olarak 0'a yaklaşmaktadır [2].

Eşitlik 1'den görüleceği gibi serada 1sı gereksiniminin hesaplanmasında çok az parametreye ihtiyaç duyulmaktadır. Ancak hesaplama için gerekli olan bu parametreler seranın sahip olduğu donanıma ve serada üretilen bitki çeşidine göre doğru olarak belirlenmelidir. Isı gereksinim katsayısı $\left(U_{c s}\right)$, örtü malzemesine ve sera donanıma bağlı ısı geçirgenlik katsayısının $(U)$ ve serada istenmeyen açıklıklardan meydan gelen hava değişimine bağlı geçirgenlik katsayısının $\left(U_{L}\right)$ toplamına eşittir $[2,4]$.

$\mathrm{U}_{\mathrm{cs}}=\mathrm{U}+\mathrm{U}_{\mathrm{L}} \quad\left(\mathrm{W} \cdot \mathrm{m}^{-2} \mathrm{~K}^{-1}\right)$

Eşitlikte;

$U$ : Örtü malzemesinin sera donanımına bağlı 1sı geçirgenlik katsayısı $\left(\mathrm{W} . \mathrm{m}^{-2} \mathrm{~K}^{-1}\right)$

$U_{L}$ : Örtü malzemesindeki istenmeyen açıklıklara bağlı 1sı geçirgenlik katsayısı $\left(\mathrm{W} . \mathrm{m}^{-2} \mathrm{~K}^{-1}\right)$

Son yillarda kurulan modern seralar oldukça yalıtkan bir şekilde inşa edilmektedirler. Belirtilen nedenle iyi yalıtılmış seralarda istenmeyen açıklıklardan meydana gelen ısı kayıplarının ihmal edilmesi, hesaplama sonuçlarını pek etkilememektedir. İyi yalıtılmış serada ortaya çıkan 1Sı akılarının analizi konusunda yapılan çalışmada, örtü iç yüzey ısı iletimi $\left(h_{i}\right)$ ile rüzgar hızı arasında anlamlı bir ilişsi belirlenememiştir [6]. Bu nedenle literatürde verilen 1 sı geçirgenlik katsayısına $(U)$ göre iyi yalıtılmış seralarda 1 sı gereksiniminin hesaplanması büyük anlam kazanmaktadır. Ancak 1S1 gereksiniminin hesaplanmasında kullanılan bu katsayı $(U)$ koşullu olarak bitkisel üretimin yapılmadığı boş seralar için uygundur. Bunun da nedeni malzemenin özelliklerine göre belirlenmiş olan bu katsayının, örtü iç yüzeyinde oluşan yoğunlaşma sonucu duyulur isıya dönüş̧en gizli 1S1 akısını kapsamamasıdır. Bitkisel üretimin yapıldığı serada örtü iç yüzeyindeki konvektif $\left(\Phi_{i k}\right)$ ve radyasyon (1şıma) 1sı akısına $\left(\Phi_{i r}\right)$ ek olarak örtü yüzeyinde ortaya çıkan yoğunlaşmaya bağlı 1Sı akısı da $\left(\Phi_{i c}\right)$ ortaya çıkmaktadır. Bu yüzden bitkisel üretimin yapıldığg serada örtü iç yüzeyinde ortaya çıkan ısı akısı eşitlik 3 yardımı ile hesaplanmaktadır [2].

$\Phi_{\mathrm{i}}=\Phi_{\mathrm{ik}}+\Phi_{\mathrm{ic}}+\Phi_{\mathrm{ir}}$

Eşitlikte;

$\Phi_{i}$ : Örtü iç yüzeyindeki ısı akısı (W)

$\Phi_{i k}$ : Örtü iç yüzey konvektif ısı akısı (W)

$\Phi_{i c}$ : Örtü iç yüzey kondensasyon 1sı akısı (W)

$\Phi_{i r}$ : Örtü iç yüzey radyasyon (1şıma) 1Sı akısı (W)

Eşitlik 3'te belirtilen 1S1 akıları için aşağıdaki 1S1 iletim ilişkisi yazılabilir.

$\mathrm{h}_{\mathrm{i}}=\mathrm{h}_{\mathrm{ik}}+\mathrm{h}_{\mathrm{ic}}+\mathrm{h}_{\mathrm{ir}} \quad\left(\mathrm{W} \mathrm{m}^{-2} \mathrm{~K}^{-1}\right)$

Eşitlikte;

$h_{i}$ : Örtü iç yüzey $1 s ı$ iletim katsayısı $\left(\mathrm{W} \mathrm{m}^{-2} \mathrm{~K}^{-1}\right)$

$h_{i k}$ : Örtü iç yüzey konvektif ısı iletim katsayısı

$h_{i c}$ : Örtü iç yüzey kondensasyon 1sı iletim katsayısı

$h_{i r}$ : Örtü iç yüzey ışıma 1sı iletim katsayısı

Konvektif 1S1 iletimi, örtü malzemesinin iç yüzeyinde ortaya çıkan hava akımına (laminar, türbülans), 1sitma sistemine (borulu isıtma, üflemeli ısıtma), serbest konveksiyon koşullarında seranın yüksekliğine ve hava ile çatı yüzey sıcaklığı arasındaki farka bağlıdır [7]. Serada 1şıma ile ortaya çıkan 1S1 akıs1 ise, 1sıtma sistemine ve radyasyon yoluyla 1sı değişiminin meydana geldiği yüzeylerin sıcaklığına bağlıdır. Radyasyon ve konveksiyon isı akısı hatasız hesaplanabilmektedir [7]. Ancak örtü iç yüzeyinde yoğunlaşma sonucu ortaya çıkan 1S1 ak1s1 $\left(\Phi_{i c}\right)$ veya kondensasyon 1s1 iletiminin $\left(h_{i c}\right)$ belirlenmesi oldukça zordur. Bunun nedeni serada ortaya çıkan transpirasyonun Yaprak/Alan İndeksine (LAI) ve bitkilerin stoma açıklıklarına bağlı olarak değişim göstermesidir. $\mathrm{Bu}$ da $1 \mathrm{~s} 1$ gereksinim katsayısını $\left(U_{c s}\right)$ ve dolayısı ile seranın 1S1 gereksinimini etkilemektedir. Is1 gereksinimi 
hesaplamalarında kullanılan isı gereksinim katsayısının $\left(U_{c S}\right)$ hangi koşullar için kullanılabileceği konusunda, özellikle hangi bitki olduğu ile ilgili, yeterli açıklama bulunmadığından $U_{c S}$ katsayısına bağlı olarak elde edilen sonuçların hata içermesine neden olmaktadır.

Yapılan bu çalışmada; farklı örtü malzemeleri için malzemenin özelliğine göre belirlenmiş 1S1 geçirgenlik katsayısı dikkate alınarak, sera donanımına ve örtü iç yüzeyindeki yoğunlaşmaya bağlı 1sı gereksinim katsayısının belirlenmesi amaçlanmıştır.

\section{METOT}

Yapılan çalışmada, sıcak sera ortamından soğuk dış ortama doğru oluşan isı akılarının, sera donanımına ve örtü malzemesinin özelliğine bağlı dirençleri esas alınarak 1sı geçirgenlik katsayısı hesaplanmıştır. Sera örtü malzemesine ve seradaki donanıma bağlı ortaya çıkan dirençler Şekil 1'de verilmiştir.

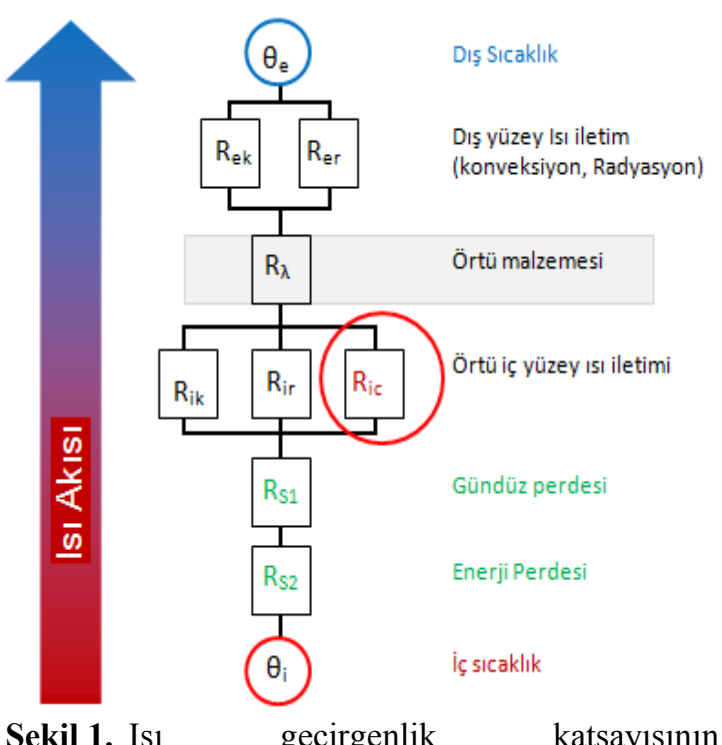

belirlenmesinde kullanılan direnç modeli

$\mathrm{Bu}$ yönteme göre, serada kullanılan ısıtma sistemi ve is1 korunumu amaciyla kullanilan farklı donanımların (1Sı perdesi, çok katlı örtü malzemesi) dikkate alınması.
Yapılan çalışmada Türkiye'de sera örtü malzemesi olarak en fazla kullanılan PE plastik, PC plakalar ve cam için ısı iletim katsayıları hesaplanmıştır. Serada 1S1 koruma amacıyla ısı perdeleri esas alınmıştır. Farklı örtü malzemelerinin ve serada 1sı perdesinin kullanılması durumunda 1sı geçirgenlik dirençleri Şekil 1'de verildiği gibi toplanarak belirlenmiş ve Eşitlik 5'te verilmiştir.

$\mathrm{R}=\left(\mathrm{R}_{\mathrm{i}}+\mathrm{R}_{\lambda}+\mathrm{R}_{\mathrm{e}}+\mathrm{R}_{\mathrm{s} 1}\right) \quad\left(\mathrm{m}^{2} \mathrm{~K} \cdot \mathrm{W}^{-1}\right)$

Eşitlikte;

$R$ : Isı iletim direnci $\left(\mathrm{m}^{2} \mathrm{~K} . \mathrm{W}^{-1}\right)$

$R_{i}$ : Örtü iç yüzey 1 sı iletim direnci $\left(\mathrm{m}^{2} \mathrm{~K} . \mathrm{W}^{-1}\right)$

$R_{\lambda}$ : Örtü malzemesi 1sı iletin direnci $\left(\mathrm{m}^{2} \mathrm{~K} . \mathrm{W}^{-1}\right)$

$R_{e}$ : Örtü dış yüzey 1 sı iletim direnci $\left(\mathrm{m}^{2} \mathrm{~K} . \mathrm{W}^{-1}\right)$

$R_{s 1}$ : Is1 perdesi 1s1 iletim direnci $\left(\mathrm{m}^{2} \mathrm{~K} . \mathrm{W}^{-1}\right)$

Farklı örtü malzemelerinin 1sı geçirgenlik katsayısı $(U)$ örtü iç, dış yüzeyinde ve örtü malzemesinde ortaya çıkan dirençlerin toplamından gidilerek Eşitlik 6 yardımı ile belirlenmiştir.

$\mathrm{U}=\left(\mathrm{R}_{\mathrm{i}}+\mathrm{R}_{\lambda}+\mathrm{R}_{\mathrm{e}}\right)^{-1} \quad\left(\mathrm{~W} \cdot \mathrm{m}^{-2} \mathrm{~K}^{-1}\right)$

Bitkisel üretimin yapılmadığı seralarda örtü iç yüzeyinde ortaya çıkan 1sı iletimi $\left(h_{i}=9\right)$ ve diş yüzey $1 \mathrm{~s} 1$ iletimi $\left(h_{e}=25 \mathrm{~W} \cdot \mathrm{m}^{-2} \mathrm{~K}^{-1}\right)$ alınmıştır $[2,4,6,8]$. Bu durumda örtü iç yüzey isı iletim direnci $\mathrm{R}_{\mathrm{i}}=0,111 \mathrm{~m}^{2} \mathrm{~K} . \mathrm{W}^{-1}$ ve örtü dış yüzey $1 \mathrm{~S} 1$ iletim direnci $\mathrm{R}_{\mathrm{e}}=0,04 \mathrm{~m}^{2} \mathrm{~K}$. $\mathrm{W}^{-1}$ olmaktadır. Örtü iç ve dış yüzey isı iletim dirençleri dikkate alınarak farklı malzemelerin laboratuvar koşullarında belirlenmiş 1sı geçirgenlik katsayılarından $(U)$ gidilerek Eşitlik 7 yardımıyla örtü malzemesinin 1s1 iletim dirençleri $\left(R_{\lambda}\right)$ hesaplanmıştır.

$R_{\lambda}=U^{-1}-R_{i}-R_{e} \quad\left(\mathrm{~m}^{2} \mathrm{~K} . \mathrm{W}^{-1}\right)$

Örtü malzemesinin dış yüzey ısı iletimi $\left(h_{e}\right)$, rüzgar hızına $\left(v_{w}\right)$ (konveksiyon) ve gökyüzü koşullarına göre (bulut, gökyüzü sıcaklığı $\theta_{s k}$ ) ortaya çıkan 1şınıma bağlıdır. 
$\mathrm{h}_{\mathrm{e}}=\frac{1}{\mathrm{R}_{\mathrm{e}}}=\mathrm{f}\left(\mathrm{v}_{\mathrm{w}}, \theta_{\mathrm{sk}}\right)$

Tek kat örtü malzemesi ile kaplı seralarda $h_{e}$ değerinin rüzgar hızına göre değişimi konusunda yeterli sayıda çalışma sonuçları vardır [7]. Serada çift veya çok katlı örtü malzemesinin kullanılması ve gökyüzünün açık olması durumunda, örtü malzemesinin dış yüzeyinde ışıma ile ortaya çıkan 1S1 akısı, sera içinden dişarıya olan ısı akısından büyüktür. Bu durumda çatı örtü malzemesinin diş yüzey sıcaklığı dış hava sıcaklığının altına düşmektedir. $\mathrm{Bu}$ koşullarda $h_{e}$ değeri negatif bir değere ulaştığından pek anlamı kalmamaktadır. Böyle durumlarda $R_{e}$ değeri $R_{\lambda}$ değerine göre çok küçük olduğundan ihmal edilebilmektedir [2].

Genelde sera örtü iç yüzeyindeki 1sı iletim direncinin hesaplanmasında, örtü iç yüzeyindeki konveksiyon ve radyasyon 1s1 ak1sı direnci dikkate alınmaktadır. Ancak bu hesaplama yöntemi bitkisel üretimin yapılmadığ 1 seralar için uygundur. Serada bitkisel üretim yapılması durumunda ortaya çıkan evapotranspirasyona ve örtü iç yüzeyindeki yoğunlaşmanın da dikkate alınması zorunludur. Bitkisel üretimin yapıldığı serada örtü iç yüzey 1sı iletim direnci Eşitlik 9 yardımı ile hesaplanmaktadır [2].

$\mathrm{R}_{\mathrm{i}}=\mathrm{R}_{\mathrm{ik}}+\mathrm{R}_{\mathrm{ir}}+\mathrm{R}_{\mathrm{ic}} \quad\left(\mathrm{m}^{2} \mathrm{~K} \cdot \mathrm{W}^{-1}\right)$

Eşitlikte;

$R_{i k}$ : Örtü iç yüzey konveksiyon 1 sı iletim direnci $\left(\mathrm{m}^{2} \mathrm{~K} . \mathrm{W}^{-1}\right)$

$R_{\text {ir }}$ : Örtü iç yüzey radyasyon 1Sı iletim direnci $\left(\mathrm{m}^{2} \mathrm{~K} . \mathrm{W}^{-1}\right)$

$R_{i c}$ : Örtü iç yüzey kondensasyon 1sı iletim direnci $\left(\mathrm{m}^{2} \mathrm{~K} . \mathrm{W}^{-1}\right)$

Sera örtüsünde ortaya çıkan 1sı iletiminde önemli olan, örtü iç yüzeyindeki 1sı iletim direncidir $\left(R_{i}\right)$. Örtü iç yüzeyinde ortaya çıkan 1sı akısı Eşitlik 3 'te verilmiştir. Örtü iç yüzeyindeki yoğunlaşmaya bağlı 1s1 akıs1, konveksiyon ve radyasyon 1s1 akısına paralel olarak ortaya çıkmaktadır. Bu durumda örtü iç yüzey 1sı iletimi Eşitlik 4'e göre toplanarak belirlenmektedir.
Bitkisel üretimin yapıldı̆̆ malzemesinde ortaya çıkan toplam isı akısının ne kadarının latent 1S1 akısıyla meydana geldiği, hesaplamalarda büyük önem arz etmektedir.

$\mathrm{P}_{\text {lat }}=\left(\mathrm{h}_{\mathrm{ic}} / \mathrm{h}_{\mathrm{i}}\right)$

Eşitlikte;

$P_{\text {lat }}$ : Örtü malzemesinde ortaya çıkan latent 1S1 akısının toplam ısı akısına oranı (-)

$h_{i c}$ : Örtü iç yüzey kondensasyon 1sı iletim katsayıs1 $\left(\mathrm{W} \mathrm{m}^{-2} \mathrm{~K}^{-1}\right)$

Örtü malzemesinde ortaya çıkan latent 1sı akısının toplam 1sı akısına oranı $\left(P_{\text {lat }}\right)$ örtü iç yüzeyinde ortaya çıkan ısı iletimin $\left(h_{i}\right)$ değerine bağlı olarak değişmektedir. Tantau [2] iyi yalıtılmış serada saksıda süs bitkisi üretiminin yapıldığı koşullarda latent 1S1 akısının toplam 1sı akısına oranını \%25-40 arasında belirlemiştir. Araştırıcı yaptığı çalışmalara dayanarak domates ve hıyar gibi büyük Yaprak/Alan İndeksine sahip bitkilerin yetiştirildiği seralarda latent 1s1 akisinın toplam 1s1 akısına oranının \%50-60 arasında alınabileceğini ifade etmektedir [2]. Yapılan bu çalışmada örtü malzemesinden oluşan toplam 1s1 akısının $\% 25, \% 40$ ve $\% 50$ 'sinin latent 1 s1 olarak ortaya çıktığı kabul edilmiş ve buna bağlı olarak hesaplamalarda örtü iç yüzey 1 sı iletimleri $h_{i}=12$, $\mathrm{h}_{\mathrm{i}}=15$ ve $\mathrm{h}_{\mathrm{i}}=18 \mathrm{~W} \cdot \mathrm{m}^{-2} \mathrm{~K}^{-1}$ olarak alınmıştır.

Serada 1S1 koruma amaciyla kullanılan farklı perdelerin 1sı iletim dirençleri $\left(R_{S}\right)$ Çizelge 1 'de verilmiştir [6].

Çizelge 1. Seralarda kullanılan farklı perdelerin 1s1 geçirgenlik dirençleri [6]

\begin{tabular}{|l|c|}
\hline Perde & $R_{S}\left(\mathrm{~m}^{2} \mathrm{~K} . \mathrm{W}^{-1}\right)$ \\
\hline Gündüz perdesi & 0,08 \\
\hline Enerji perdesi & 0,14 \\
\hline Gölgeleme perdesi & 0,36 \\
\hline
\end{tabular}

Serada kullanılan 1S1 perdelerine bağlı olarak hesaplanan isı geçirgenlik katsayılarında Çizelge 1'de verilen direnç değerleri esas alınmıştır. Serada farklı örtü malzemesi ve 1S1 koruma amacıyla farklı perdelerin kullanılması durumunda 
Şekil 1'de verilen direnç modelinde görüldüğü gibi kullanılan örtü malzemesi ve perdelerin 1S1 geçirgenlik dirençleri toplanarak $U$ katsayıları hesaplanmıştır.

$\mathrm{U}=\left(\mathrm{R}_{\mathrm{i}}+\mathrm{R}_{\lambda}+\mathrm{R}_{\mathrm{e}}+\mathrm{R}_{\mathrm{s} 1}+\mathrm{R}_{\mathrm{s} 2}\right)^{-1} \quad\left(\mathrm{~W} \cdot \mathrm{m}^{-2} \mathrm{~K}^{-1}\right)$

Serada çatı iç yüzeyinde ortaya çıkan yoğunlaşma miktarının belirlenmesi için çatı iç yüzey sıcaklığının bilinmesi gereklidir. Çatı iç yüzey sıcaklığının hesaplanması Eşitlik 12 yardımı ile yapılmıştır [2].

$\theta_{\mathrm{si}}=\left(\mathrm{R}_{\lambda}+\mathrm{R}_{\mathrm{e}}\right) * \mathrm{U} *\left(\theta_{\mathrm{i}}-\theta_{\mathrm{e}}\right)+\theta_{\mathrm{e}}\left({ }^{\circ} \mathrm{C}\right)$

Eşitlikte;

$\theta_{s i}:$ Örtü iç yüzey sıcaklığ $1\left({ }^{\circ} \mathrm{C}\right)$

Örtü iç yüzeyinde ortaya çıkan yoğunlaşma serada nem miktarını etkilemektedir. Örtü iç yüzeyinde yoğunlaşan su miktarı (Co) Eşitlik 13 yardımı ile hesaplanmıştır [2].

$\mathrm{Co}=\mathrm{h}_{\mathrm{ic}} *\left(\theta_{\mathrm{i}}-\theta_{\mathrm{e}}\right) / \mathrm{r}_{0} * 3600\left(\mathrm{~g} \cdot \mathrm{m}^{-2} \mathrm{~h}^{-1}\right)$
Eşitlik 13'te;

Co: Örtü iç yüzeyinde yoğunlaşan su $\left(\mathrm{g} \cdot \mathrm{m}^{-2} \mathrm{~h}^{-1}\right)$

$r_{0}$ : Buharlaşma 1sısı $\left({\left.\mathrm{J} . \mathrm{kg}^{-1}\right)}^{-1}\right.$

\section{BULGULAR}

Serada farklı örtü malzemesi ve 1S1 koruma amacıyla farklı perdelerin kullanılması durumunda Şekil 1'de verilen direnç modelinden gidilerek Eşitlik 11'e göre farklı donanımlar için hesaplanan 1S1 geçirgenlik katsayıları Çizelge 2'de verilmiştir. $\mathrm{PE}$ plastiğin $1 \mathrm{~s}$ iletim direncinin $\left(R_{\lambda}\right)$ negatif çıkması PE'nin uzun dalgalı 1sı 1şınlarını geçirmesinden kaynaklanmaktadır [2]. Çizelge 2'den de görüleceği gibi bitkisel üretimin yapıldığı seralarda artan örtü iç yüzey 1sı iletimine bağlı olarak 1sı geçirgenlik katsayısı da artmaktadır. Tek kat PE plastikle kaplı boş sera için hesaplanan 1sı geçirgenlik katsayısı 7 W.m $\mathrm{m}^{-2} \mathrm{~K}^{-1}$ iken, domates ve hıyar gibi büyük Yaprak/Alan İndeksine (LAI) sahip bitkilerin yetiştirildiği seralarda $\left(h_{i}=18\right.$ $\left.\mathrm{W} . \mathrm{m}^{-2} \mathrm{~K}^{-1}\right) U$ değeri $\% 64$ artarak 11,5 W. $\mathrm{m}^{-2} \mathrm{~K}^{-1}$ değerine yükselmektedir.

Çizelge 2. Sera iç yüzey 1sı iletimine $\left(h_{i}\right)$ bağlı hesaplanmış 1sı tüketim katsayıları

\begin{tabular}{|c|c|c|c|c|c|}
\hline $\boldsymbol{R}_{\boldsymbol{e}}=0,04 \mathrm{~m}^{2} \mathrm{~K} . \mathrm{W}^{-1}$ & $\boldsymbol{h}_{\boldsymbol{i}}=9$ & \multirow{3}{*}{$\boldsymbol{R}_{\lambda}$} & $\boldsymbol{h}_{\boldsymbol{i}}=12$ & $\boldsymbol{h}_{\boldsymbol{i}}=15$ & $\boldsymbol{h}_{\boldsymbol{i}}=18$ \\
\hline \multirow[t]{2}{*}{$\boldsymbol{R}_{\boldsymbol{i}} \mathrm{m}^{2} \mathrm{~K} . \mathrm{W}^{-1}$} & 0,11111 & & 0,08333 & 0,06666 & 0,05555 \\
\hline & $U$ & & $U$ & $U$ & $U$ \\
\hline Plastik örtü malzemeleri & W. $\mathrm{m}^{-2} \mathrm{~K}^{-1}$ & $\mathrm{~m}^{2} \mathrm{~K} . \mathrm{W}^{-1}$ & W. $\mathrm{m}^{-2} \mathrm{~K}^{-1}$ & W. $\mathrm{m}^{-2} \mathrm{~K}^{-1}$ & W. $\mathrm{m}^{-2} \mathrm{~K}^{-1}$ \\
\hline Tek kat PE UV katkılı & 7,0 & $-0,01$ & 8,7 & 10,2 & 11,5 \\
\hline Çift kat PE UV katkılı & 3,4 & 0,14 & 3,8 & 4,0 & 4,2 \\
\hline \multicolumn{6}{|l|}{ Cam ve sert örtü malzemeleri } \\
\hline Tek kat cam & 6,0 & 0,02 & 7,2 & 8,2 & 9,0 \\
\hline Çift kat cam & 3,0 & 0,18 & 3,3 & 3,5 & 3,6 \\
\hline PC 6 mm aralıklı & 3,6 & 0,13 & 4,0 & 4,3 & 4,5 \\
\hline PC $10 \mathrm{~mm}$ aralıklı & 3,2 & 0,16 & 3,5 & 3,7 & 3,9 \\
\hline PC $16 \mathrm{~mm}$ aralıklı & 1,8 & 0,40 & 1,9 & 2,0 & 2,0 \\
\hline \multicolumn{6}{|l|}{ Farklı örtü malzemeleri + Farklı perdeler } \\
\hline Tek kat cam + Enerji perdesi & 3,26 & 0,14 & 3,59 & 3,81 & 3,98 \\
\hline Tek kat cam + Gündüz + Enerji perdesi & 2,59 & 0,22 & 2,75 & 2,88 & 2,98 \\
\hline Tek kat cam +2 enerji + Gölgeleme perdesi & 1,34 & 0,58 & 1,38 & 1,42 & 1,44 \\
\hline PE Plastik + Enerji perdesi & 3,54 & 0,14 & 3,95 & 4,23 & 4,43 \\
\hline PE Plastik + Gündüz + Enerji perdesi & 2,76 & 0,22 & 3,00 & 3,16 & 3,27 \\
\hline
\end{tabular}

Çizelge 2'de görüleceği gibi serada üretimin yapılmadığ 1 koşullarda $\left(h_{i}=9 \mathrm{~W} \mathrm{~m}^{-2} \mathrm{~K}^{-1}\right)$ artan $1 \mathrm{~s} 1$ koruma önlemlerine (çift katlı örtü, 1sı perdesi) bağlı 1sı geçirgenlik katsayısı $(U)$ ile serada üretimin yapıldığı koşullardaki $\left(\mathrm{h}_{\mathrm{i}}=12, \mathrm{~h}_{\mathrm{i}}=15\right.$ ve $\left.\mathrm{h}_{\mathrm{i}}=18 \mathrm{~W} \cdot \mathrm{m}^{-2} \mathrm{~K}^{-1}\right) \quad U$ değerleri arasındaki fark azalmaktadır. Serada 1sı koruma amacıyla farklı sayıda perdenin kullanılması durumunda $U$ katsayısı, kullanılan her perdenin 1sı geçirgenlik direnci $\left(R_{S}\right)$ eklenerek belirlenmelidir. Çizelge 2'de 
hesaplanan $U$ değerleri serada üretilen bitkinin transpirasyonuna bağlı ortaya çıkan örtü iç yüzey 1sı iletim katsayıları için geçerlidirler.

Tek kat örtü malzemesi ile kaplı seralarda örtü yüzey sıcaklığına bağlı olarak ortaya çıkan yoğunlaşma çift kat örtü ile kaplı seralara göre daha fazadır. Örtü iç yüzeyindeki yoğunlaşamaya aynı zamanda dış sicaklıkta etki etmektedir. Isı perdelerinin kullanıldığı serada yoğunlaşmanın sadece örtü iç yüzeyinde oluştuğu ve 1 sı perdelerinde yoğunlaşmanın meydana gelmediği kabul edilmiştir.

Örtü iç yüzey 1sı iletimlerinin latent 1sı iletimine oranı $\% 25-40$ ve 50 olduğunda, kondensasyon 1s1 iletimi $h_{i c}=3, h_{i c}=6 \mathrm{ve} h_{i c}=9 \mathrm{~W} \cdot \mathrm{m}^{-2} \mathrm{~K}^{-1}$ olarak alınabilmektedir [2]. Serada sıcaklığın $\theta_{i}=20{ }^{\circ} \mathrm{C}$, dış sıcaklığın $\theta_{\mathrm{e}}=-5^{\circ} \mathrm{C}$ ve $\theta_{\mathrm{e}}=5^{\circ} \mathrm{C}$ olarak kabul edildiği koşullarda sera örtüsü iç yüzeyinde ortaya çıkan yoğunlaşma miktarı hesaplanarak Çizelge 3'te verilmiştir. Çizelge 3 'te görüldüğü gibi örtü iç yüzeyindeki yoğunlaşma miktarı örtü iç yüzeyi sıcaklığına bağlı olarak değişmektedir

Serada alınan ısı koruma önlemlerine bağlı olarak azalan çatı iç yüzey sıcaklığına ve azalan $U$ değerlerine veya artan dış sıcaklık değerlerine bağlı olarak örtü iç yüzeyinde ortaya çıkan yoğunlaşma azalmaktadır. Bu da sera yalıtımının iyileştirilmesi durumunda perde altındaki nem değerlerinin yükselmesi anlamına gelmektedir. Is1 perdeli modern seralarda sıkça ortaya çıkan bu durum, bitkiler için önemli olan Ca gibi besin maddelerinin alınmasını azalttığı gibi, mantar hastalıklarının ortaya çıkma riskini artırmaktadır.

Çizelge 3. Farklı örtü malzemelerinin iç yüzey 1sı iletimlerine ve sera iç-dış sıcaklıklarına göre örtü iç yüzey sıcaklıkları ve yoğunlaşan su miktarı

\begin{tabular}{|c|c|c|c|c|c|c|c|c|c|c|c|c|c|c|}
\hline $\boldsymbol{R}_{\boldsymbol{e}}=0,04 \mathrm{~m}^{2} \mathrm{~K} \cdot \mathrm{W}^{-1}$ & $\boldsymbol{h}_{i}=9$ & $\boldsymbol{h}_{\boldsymbol{i}}=12$ & $\boldsymbol{h}_{\boldsymbol{i}}=15$ & $\boldsymbol{h}_{\boldsymbol{i}} 18$ & $\boldsymbol{h}_{\boldsymbol{i}}=12$ & $\boldsymbol{h}_{\boldsymbol{i}}=15$ & $\boldsymbol{h}_{\boldsymbol{i}}=18$ & $\boldsymbol{h}_{\boldsymbol{i}}=9$ & \begin{tabular}{|c|}
$\boldsymbol{h}_{\boldsymbol{i}}$ \\
$=12$ \\
\end{tabular} & \begin{tabular}{|c|}
$\boldsymbol{h}_{\boldsymbol{i}}=1$ \\
5
\end{tabular} & \begin{tabular}{|c|}
$\boldsymbol{h}_{\boldsymbol{i}}$ \\
$=18$ \\
\end{tabular} & \begin{tabular}{|c|}
$\boldsymbol{h}_{\boldsymbol{i}}=1$ \\
2 \\
\end{tabular} & $\begin{array}{c}\begin{array}{c}\boldsymbol{h}_{\boldsymbol{i}} \\
=15\end{array} \\
\end{array}$ & \begin{tabular}{|c|}
$\boldsymbol{h}_{\boldsymbol{i}}=1$ \\
8
\end{tabular} \\
\hline Dış Sıcaklık & \multicolumn{4}{|c|}{$\theta_{e^{-}-5^{\circ} \mathrm{C}}$} & \multicolumn{3}{|c|}{$\theta_{e^{-5}{ }^{\circ} \mathrm{C}}$} & \multicolumn{4}{|c|}{$\theta_{e}+5^{\circ} \mathrm{C}$} & \multicolumn{3}{|c|}{$\theta_{e}+5^{\circ} \mathrm{C}$} \\
\hline & \multicolumn{4}{|c|}{ Örtü iç yüzey sıcaklığı $\left(\theta_{s i}\right)$} & \multicolumn{3}{|c|}{ Yoğunlaşma $(\mathrm{Co})$} & \multicolumn{4}{|c|}{$\begin{array}{c}\text { Örtü iç yüzey sıcaklı̆̆ı } \\
\left(\theta_{s i}\right)\end{array}$} & \multicolumn{3}{|c|}{ Yoğunlaşma $(\mathrm{Co})$} \\
\hline Plastik örẗ̈ & \multicolumn{4}{|c|}{${ }^{\circ} \mathrm{C}$} & \multicolumn{3}{|c|}{ g. $m^{-2} h^{-1}$} & \multicolumn{4}{|c|}{${ }^{\circ} \mathrm{C}$} & \multicolumn{3}{|c|}{ g. $m^{-2} h^{-1}$} \\
\hline Tek kat PE UV katkılı & 0,6 & 1,9 & 3,1 & 4,1 & 87 & 162 & 228 & 8,3 & 9,1 & 9,8 & 10,5 & 52 & 97 & 137 \\
\hline Çift kat PE UV katkılı & 10,6 & 12,2 & 13,3 & 14,2 & 37 & 64 & 84 & 14,3 & 15,3 & 16,0 & 16,5 & 22 & 38 & 50 \\
\hline \multicolumn{15}{|l|}{ Cam ve sert örtü malzemeleri } \\
\hline Tek kat cam & 3 & 0 & 6,4 & 7,5 & 12 & 131 & 179 & 10,0 & 11,0 & $\mid 11,8$ & 12,5 & 43 & 78 & 108 \\
\hline Çift. & 1,7 & 13,2 & 14,2 & 15,0 & 33 & 55 & 72 & 15,0 & 15,9 & 16,5 & 17,0 & 20 & 33 & 43 \\
\hline PC 61 & 10,0 & 11,7 & 12,9 & 13,8 & 40 & 6 & 90 & 14,0 & 15,0 & 15,7 & 16,3 & 24 & 41 & 54 \\
\hline PC 1 & 11,1 & 12,7 & 13,8 & 14,6 & 3. & 60 & 78 & 14,7 & 15,6 & 16,3 & 16,8 & 21 & 36 & 47 \\
\hline PC $16 \mathrm{~mm}$ aralıklı & 15,0 & 16,1 & 16,7 & 17,2 & 19 & 3 & 1 & 17,0 & 17,6 & 18,0 & 18,3 & 11 & 19 & 24 \\
\hline \multicolumn{15}{|c|}{ Farklı örtü malzemeleri + Farklı perdeler } \\
\hline Tek kat cam + Enerji perdesi & $-0,5$ & 0,0 & 0,3 & 0,5 & 38 & 63 & 93 & 7,7 & 8,0 & 8,2 & 8,3 & 23 & 38 & 56 \\
\hline $\begin{array}{l}\text { Tek kat cam + Gündüz + Enerji } \\
\text { perdesi }\end{array}$ & $-1,4$ & $-1,2$ & $-1,0$ & $-0,9$ &  & 47 & 66 & 7,2 & 7,3 & 7,4 & 7,5 & 17 & 28 & 40 \\
\hline $\begin{array}{l}\text { Tek kat cam }+2 \text { enerji }+ \\
\text { Gölgeleme per. }\end{array}$ & $-3,1$ & $-3,1$ & $-3,0$ & $-3,0$ & 14 & 23 & 32 & 6,1 & 6,2 & 6,2 & 6,2 & 8 & 14 & 19 \\
\hline PE Plastik + Enerji perdesi & $-2,2$ & $-1,9$ & $-1,6$ & $-1,5$ & 42 & 69 & 103 & 6,7 & 6,9 & 7,0 & 7,1 & 25 & 41 & 62 \\
\hline $\begin{array}{l}\text { PE Plastik + Gündüz + Enerji } \\
\text { perdesi }\end{array}$ & $-2,8$ & $-2,6$ & $-2,5$ & $-2,4$ & 29 & 50 & 71 & 6,3 & 6,4 & 6,5 & 6,6 & 18 & 30 & 43 \\
\hline
\end{tabular}

\section{SONUÇ VE TARTIŞMA}

Serada 1Sı akılarına bağlı dirençlerin toplamından gidilerek belirlenen isı iletim katsayısı ile uygulamada yapılan denemelerden elde edilen sonuçlar uyum göstermektedir. Doğan ve Baytorun [9] üretici koşullarında ısı perdeli PE plastik serada yaptıkları ölçümlerde örtü malzemesinden transmisyonla ortaya çıan 1S1 iletimini 4,08 W.m $\mathrm{m}^{-2} \mathrm{~K}^{-1}$ olarak bulmuşlardır. Yapılan bu çalışmada PE plastikle kaplı 1sı perdeli serada dirençlerin toplamından gidilerek örtü malzemesinden transmisyonla ortaya çıkan 1s1 iletim katsayısı $h_{i}=15$ W. $\mathrm{m}^{-2} \mathrm{~K}^{-1}$ için $4,23 \mathrm{~W} \cdot \mathrm{m}^{-2} \mathrm{~K}^{-1}$ 
olarak belirlenmiștir. Elde edilen bu sonuçlar yalıtımı iyi seralarda direnç değerlerinden gidilerek hesaplanan 1s1 iletim katsayılarının 1s1 gereksinimi hesaplamalarında kolaylıkla kullanılabileceğini göstermektedir. Nitekim dirençlerden gidilerek hesaplanan isı iletim katsayıları uygulamadan elde edilen sonuçlarla iyi uyum gösterdiği Tantau [6] tarafından da belirlenmiştir.

Çift veya çok katlı örtü malzemesi ile kaplı seralarda direnç yöntemine göre yapılan hesaplama sonucunda ortaya çıkan hatalar, tek kat örtü malzemesi ile kaplı seralarda ortaya çıkacak hatalardan daha küçüktür [2]. Bu durumu kullanılan yöntemdeki direnç metoduyla açıklamak mümkündür. Seralarda kullanılan tek katlı örtü malzemesinin 1s1 geçirgenlik direnci oldukça küçüktür. Tek kat örtü ile kaplı seralarda $R_{\lambda}=0$ $\mathrm{m}^{2} \mathrm{~K} . \mathrm{W}^{-1}$ a a yakın olduğundan, örtünün iç ve dış yüzeyinde ortaya çıkan 1sı iletim dirençleri, toplam direnci, dolayısı ile 1sı geçirgenlik katsayısını $(U)$ belirlemektedir. Sera iç ve dış yüzey 1sı iletim dirençleri de farklı faktörlere bağlı olarak değişim gösterdiklerinden tek kat örtü malzemesi için hesaplanan $U$ değeri büyük sapmalar göstermektedir. Çift veya çok katlı örtü ile kaplı seralarda ise örtü malzemesinin 1sı geçirgenlik direnci $\left(R_{\lambda}\right)$ yüksek olduğundan 1sı geçirgenlik katsayısında etkili olmaktadır.

Örtü malzemesinin iç yüzey sicaklığı örtü iç yüzeyinde yoğunlaşan su miktarını belirlemektedir. Seranın iyi yalıtılması, örtü malzemesinin 1S1 geçirgenlik katsayısının $(U)$ küçük olması ve dış sıcaklığın yükselmesi, örtü iç yüzeyi sıcaklığının yükselmesine neden olmaktadır. Bu koşullarda yüksek sıcaklığa sahip bitki yaprakları ve örtü malzemesi arasında 1şıma ile ortaya çıkan 1sı akısı azalmakta ve bitki yaprak sıcaklığı yükselmektedir. $\mathrm{Bu}$ durum hava neminin bitki yaprakları üzerinde yoğunlaşma tehlikesini ortadan kaldırmaktadır.

Örtü iç yüzey sıcaklığ 1 yoğunlaşmaya önemli derecede etki etmektedir. Çift katlı örtü malzemesi ile kaplı serada örtü iç yüzey sıcaklığı yüksek olduğundan yoğunlaşma olmamaktadır. Yoğunlaşma nemin aşırı yükseldiği koşullarda ortaya çıkmaktadır. Çok katlı örtü malzemesinin iç yüzeyinde ortaya çıkan yoğunlaşma tek kat örtü malzemesi ile kaplı seraya göre oldukça azdır. Serada kullanılan perdelerin hava nemine etkileri ilginçtir. Serada kullanılan perdeler kapalı tutulduklarında hava neminin çatı bölgesine geçmesini engellerler. Perdeler aynı zamanda çatı örtü yüzeyi sıcaklığının düşmesine de neden olurlar. $\mathrm{Bu}$ durumda bitki sıra aralarındaki havanın nem içeriği ile çatı bölgesindeki havanın doyum değerleri arasında büyük bir fark ortaya çıkmaktadır.

Sonuç olarak seralarda ısı koruma amacıyla alınan tüm önlemlerde hava neminin yükselmesi kaçınılmazdır. Serada ortaya çıkan yüksek nemin uzaklaştırılması amacıyla alınacak önlemler enerji gerektirmektedir. Ayrıca havalandırma ile dışarı atılan hava neminin içerisinde azımsanmayacak derecede yüksek 1sı enerjisinin bulunduğu unutulmamalıdır [3]. Serada yüksek nemin ortaya çıkmaması amacıyla uygun sulama sisteminin seçilmesi en ucuz ve en basit önlemlerden bir tanesidir. Aynı zamanda serada yapılan dikimde yeterli bir bitki sıra arası ve sıra üstü açıklığının bırakılması da bitki aralarındaki nemin kontrolü açısından önemlidir. Sık dikilmiş bitki aralarında yüksek nemin yaratacağı tehlikeler oldukça büyüktür. Serada aynı zamanda yatay ve dikey eksen boyunca ortaya çıkan sıcaklık değişimleri nem değişimlerine neden olacağ 1 için düşük sıcaklıkların ortaya çıktığı kenar ve köşelerde yoğunlaşmanın ortaya çıkma tehlikesi bulunmaktadır. $\mathrm{Bu}$ durum hastalıkların ortaya çıkması açısından oldukça tehlikelidir. Böyle durumlarda serada havanın vantilatörlerle karıştırılması en uygun çözümdür. Serada havanın karıştırılması durumunda hava neminin \%90'lara yükselmesi herhangi bir sorun yaratmamaktadır [2].

\section{KAYNAKLAR}

1. Baytorun, A.N., Üstün, S., Akyüz, A., Çaylı, A., 2017. Antalya İklim Koşullarında Farklı Donanımlara Sahip Seraların Isı Enerjisi Gereksiniminin Belirlenmesi. Türk Tarım-Gıda Bilim ve Teknoloji Dergisi, 5(2), 144-152.

2. Tantau, H.J., 2013. Wärmebedarf Von Gewächshäusern Unter Berücksichtigung des Latenten Wärmetransportes. Landtechnik 68(1), 43-49. 
3. Baytorun, A.N., Akyüz, A., Üstün, S., 2016. Seralarda Isıtma Sistemlerinin Modellemesi ve Karar Verme Aşamasında Bilimsel Verilere Dayalı Uzman Sistemin Geliştirilmesi. TÜBİTAK Proje No: 1140533

4. Von Zabeltitz, C., 1986. Gewächshäuser. Verlag Eugen Ulmer. Stuttgart

5. Meyer, J., 2008. Nomenklatur und Definitionen Bericht zur Bestimmung und Bewertung des Energiebedarfs von Gewächshäusern. KTBL Workshop. 17 September 2008, 14-22.

6. Tantau, H.J., 2012. Das Niedrigenergie Gewächshaus-Methode zur Analyse der Wärmeströme und der PAR-Durchlässigkeit. Landtechnik 67(3), 196-204.

7. Tantau, H.J., 1975. Der Einfluss von Einfachund Doppelbedachungen auf das Klima und den Wärmehaushalt von Gewächshäusern. Gartenbautechnische Informationen Heft 4. Institut für Technik in Gartenbau und Landwirtschaft, Universität Hannover.

8. Olgun, M., 2011. Tarımsal Yapılar. Ankara Üniversitesi Ziraat Fakültesi. Yayın No: 1577, Ders Kitabı: 529, 445.

9. Doğan, G.Ç., Baytorun, A.N., 2018. Is1 Korumal1 Modern Seralarda Üretici Koşullarında Toplam Isı Gereksinim Katsayısının Belirlenmesi. Ç.Ü. Fen ve Mühendislik Bilimleri Dergisi, 35-8, 20-29. 
